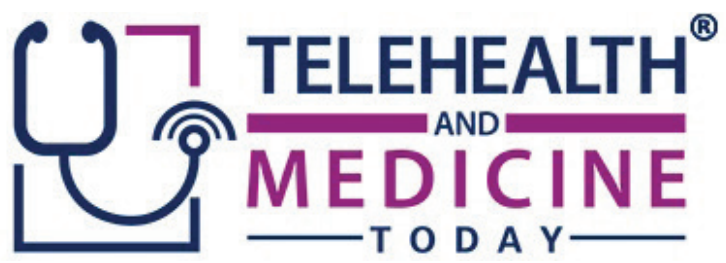

\title{
Telehealth: Is It Only for the Rural Areas? A Review of Its Wider Use
}

\section{Sadat Muzammil}

Affiliation: Folly Lane Medical Centre, Warrington, Cheshire, UK

Corresponding Author: Sadat Muzammil, sadatmuzammil@doctors.org.uk

Keywords: Cost Saving, Innovation, Patient Care, Technical Resources, Telehealth

Section: Narrative/Systematic Reviews/Meta-Analysis

Telehealth (also known as telemedicine, digital medicine) is a relatively new concept in healthcare provision, which is perceived as a useful mode of managing patients at remote locations. As this technology evolves, the need arises to explore telehealth as part of holistic care. Much literature on telehealth is available but most are specialty-based or focus on one or two aspects of care provision. This article focuses on the four main building blocks of telehealth: perception by healthcare staff, perception by patients, quality of Internet and technology, and cost effectiveness based on 2 years of published literature.

$\mathrm{T}$ The global population is living longer, and resources are overstretched. There is a shortage of healthcare staff, and patients are more aware of their health needs. Keeping this in mind, new and innovative ways of healthcare provision are required that utilize smart technology to deliver cost-effective care to meet the health needs of the global population. This article sheds light on research on telehealth along with a perspective of its benefits in healthcare delivery.

\section{METHODS}

A literature search was conducted through PubMed, Medline, and Google Scholar. Search terms included telemedicine, telehealth, e-health, and articles published in 2018 and 2019. Inclusion criteria included studies with the above information, with literature from all specialties considered. Only well-designed and rigorously carried out studies with clear results and conclusion are included here.

\section{RESULTS}

\section{Telehealth from the Healthcare Staff}

\section{Perspective}

Telehealth education is a well-known practice in theory, with health staffs and medical students 
experienced in its use for educational purposes. However, managing patients is still a novel concept. ${ }^{1,2}$

Awareness of telehealth among nurses and general practitioners is lacking, as reported in studies from New Zealand and the Czech Republic. ${ }^{3,4}$ Although doctors and nurses generally have a positive view of telehealth, there are concerns over the quality of healthcare provision, continuity of care, the inability to conduct patient examination, and the legality of telehealth, as expressed by the healthcare staff. ${ }^{5}$ These are compounded by hesitation to use technology, such as video consultations, and a general resistance to change.

Importantly, there are studies reporting a change in the trend amongst nurses and doctors in managing chronic conditions such as diabetes. ${ }^{6}$ For example, telehealth has been used to educate healthcare providers in rural Kenya where Internet access was primarily smartphone-based. ${ }^{7}$

If telehealth is introduced early in the clinical curriculum, perhaps the staff will feel more comfortable with it. A recent study of postlicense-level nurses demonstrated confidence on their learning in clinical areas. ${ }^{8}$

Telehealth is being used to care for surgical patients in remote areas, to help surgeons assist other specialists in the office, as well as to teach the next generation of surgeons. There are many opportunities for surgeons to utilize this technology to optimize their practice. ${ }^{9}$ In order to provide a successful and persistent telehealth service healthcare, the staff need continuous programmatic training and education, which communicates the clinical value of telehealth technology along with its opportunities and benefits. ${ }^{10,11}$ Every specialty has its unique challenges in telehealth application in spite of the efforts toward minimizing barriers for training and implementing procedures at the provider, system, and patient levels. ${ }^{12}$

\section{Clinical Application of Telehealth and Patient Opinions}

There are several factors to consider. Patients in urban regions might have a different view versus those living in remote and rural areas; but in all cases, patients prefer to see a healthcare provider at their convenience. In rural and underserved areas, there are challenges in healthcare delivery due to the lack of healthcare providers and specialists, unsuitable infrastructure, and long distances to travel to receive care.

\section{Surgery}

A study of postoperative surgical patients found that telemonitoring was associated with increased patient satisfaction. Additional findings from a prospective randomized study in the United States revealed that patients embraced telehealth technology and took advantage of increased access to healthcareprofessionals. ${ }^{13}$

\section{Ophthalmology}

Tele-ophthalmology is accepted in some parts of the world. In the United States, it remains widely underutilized. Yet, a small study highlighted the ability of tele-ophthalmology to close the gap in acute eye care, most prominently in rural regions. ${ }^{14}$ A study in Ethiopia conducted by Canadian ophthalmologists reported that through a tele-glaucoma consultation, a glaucoma specialist provided remote diagnosis and management recommendations. It was concluded that the value of tele-glaucoma would be in triaging patients who require more urgent management and identifying the disease at an earlier stage. ${ }^{15}$

\section{Orthopedics}

Orthopedic telehealth helped to significantly reduce waiting times and optimize travel times and expenditures in Chile. ${ }^{16}$ 


\section{Pediatrics}

A review of surgery in the United States revealed that telehealth services have the potential to enhance the reach of tertiary care for children in rural and underserved areas where surgical and trauma specialty care is not readily available. ${ }^{17}$ For neonatal care, telehealth may be used to access specialists in remote areas through online communication methods where telehealth provides effective communication links with neonatal specialists and encourages family-centered care. Authors reported however that positive outcomes require good preimplementation preparation. ${ }^{18,19}$

\section{Critical care}

In the adult intensive care unit (ICU), telemedicine is an established entity, which not only improves the effectiveness, efficiency, and safety of critical care but also serves as a tool to combat staffing shortages and resource-limited environments, including technical issues, financial concerns, and organizational elements. ${ }^{20}$ A review of ICU telemedicine found lower mortality, shorter length of stay, and improved best practice compliance when implemented effectively. The value lies in how well the model is applied and integrated into staff, infrastructure. Tele-ICU improves access to high-quality critical care through a variety of information technology solutions. $^{21,22}$

\section{Psychiatry}

Telepsychiatry is a new venue for managing pediatric depression. A study in the United States reported that sessions feel authentic and treatment outcomes meet and sometimes exceed those of sessions conducted in traditional venues. ${ }^{23}$ Furthermore, regarding pediatric care, evidence supports tele-practice as an effective model to deliver family-centered early intervention for children who are deaf or hard of hearing, although more research is needed. ${ }^{24}$

\section{Hepatology}

Studies, including randomized controlled trials in the United States and Spain, support the value of telehealth for patients with hepatitis $\mathrm{C}$ virus by increasing preventative measures and managing liver cirrhosis. Also, among patients with liver transplants, there is improved adherence to treatment and patient satisfaction, with an opportunity for personalized care ${ }^{25-27}$

In spite of the advantages of telemedicine, barriers to integration due to reimbursement and up-front cost remain. Nevertheless, it is an essential part in providing suitable care for those facing geographic and economic obstacles. ${ }^{28}$ Studies that report challenges in telehealth application also raise issues with its limitations.

\section{Cardiology}

A study of self-care for patients with heart failure in Iran showed that tele-monitoring improved self-care behaviors for heart failure but did not reduce read mission rates. ${ }^{29}$ In a recent meta-analysis, there were significant obstacles in the implementation of improved care for ischemic heart disease and moderate-quality evidence that telemedicine strategies. In particular, electrocardiogram transmission combined with the usual care for acute myocardial infraction, are associated with reduced in-hospital mortality and very low-quality evidence that they reduce door-to-balloon time, 30-day mortality, and long-term mortality. ${ }^{30}$ In contrast, a meta-analysis of the effectiveness in heart failure reported that compared with conventional healthcare, telemedicine systems with medical support are more effective for adults with heart failure, particularly in reducing all-cause hospitalization, cardiac hospitalization, all-cause mortality, cardiac mortality, and length of stay. ${ }^{31}$ 


\section{Migraine}

In a year-long randomized clinical trial in the United States, patients with severe migrainerelated disability found telemedicine to be a feasible and an effective alternative to in-office visits for follow-up of migraine care, with the potential for patients to get better access because of convenience, with higher physician productivity. ${ }^{32}$

\section{Parkinson disease}

A national online survey in the United States of patients with Parkinson disease reported that $76 \%$ indicated high interest. Advantages included access to specialists $(62 \%)$, convenience $(60 \%)$, and time savings (59\%), disadvantages included the lack of hands-on care (69\%), lack of intimacy $(43 \%)$, and technical difficulties $(37 \%) .{ }^{33}$

\section{Insomnia}

A study of military veteran scared for by the United States Department of Veterans Affairs reported that most sleep programs are understaffed, with lengthy wait times for appointments. Implementing a telehealth program might partly resolve this situation. ${ }^{34}$

\section{Dementia}

Regarding management of elderly patients with dementia, the reported benefits of telemedicine include reduced emergency department (ED) attendances and access to specialists for rural patients. Satisfaction with home visits was high and equal to in-clinic visits. ${ }^{35,36}$ However, challenges remain, including how to best implement and optimize telemedicine for patients with dementia who suffer from acute illnesses. ${ }^{35}$

\section{Dermatology}

Dermatology services found telemedicine to be particularly helpful in view of recent studies where over 30,000 patients with over 55,000 lesions were diagnosed in a 1 -year project in
Brazil. Dermatology services were more accessible and more efficient following implementation of tele-dermatology. ${ }^{37,38}$ Challenges include addressing technical issues in the software and the platform. ${ }^{37}$

\section{Internal medicine}

With regard to telehealth and internal medicine, there is mixed evidence. In a cluster-randomized control trial of patients with type 2 diabetes, there was limited benefit of replacing telemedicine with the current practice of self-monitoring of blood glucose. More innovative methods to improve patient engagement in diabetes care are needed. ${ }^{39}$

\section{Eating disorders}

Application of teletherapy for eating disorders through videoconferencing-based psychotherapy services is minimal. In one study, the results suggest that this treatment format leads to significant improvements in clinical symptoms and is well accepted by patients. However, success starts with careful planning and thoughtful application. ${ }^{40}$

\section{Hemophilia}

Preliminary evidence from a review in China on self-management of hemophilia suggests that telehealth-delivered interventions could improve adherence to medication use and promote independence in disease management, although support from a dedicated network of hemophilia specialists and technical staff will be required to maintain the technology. ${ }^{41}$

\section{Rheumatology}

A telemedicine study of more than 4,800 patients over 5years by a rheumatologist in the United States who was aided by a general physician and a nurse at a local charity hospital in northeastern Iran, with a catchment area that includes rural regions extending to the border of Afghanistan, reported that this option was becoming an 
Table 1. Most common rheumatic disorders managed through telemedicine by a US-based rheumatologist for 4,800 patients living in northeastern $\operatorname{Iran}^{42}$

\begin{tabular}{|lcc|}
\hline Diagnosis & $\mathbf{n}$ & $\mathbf{\%}$ \\
\hline Osteoarthritis & 1,149 & 23.6 \\
\hline Rheumatoid arthritis & 653 & 13.4 \\
\hline Axial spondyloarthropathies & 647 & 13.3 \\
\hline Lumbar spinal stenosis & 427 & 8.8 \\
\hline Meniscal tear of the knee & 326 & 6.7 \\
\hline Psoriatic arthritis & 217 & 4.5 \\
\hline Fibromyalgia & 169 & 3.5 \\
\hline Lupus & 19 & 0.4 \\
\hline
\end{tabular}

acceptable modality for successful evaluation and management of a wide range of rheumatic diseases in a region with limited access to rheumatologic care including biologic agents (Table 1). ${ }^{42}$

In surgical specialties, telehealth shows promising results, although further research and funding are needed. In ear, nose and throat cases, telehealth, audiological telemedical measurements even after Cochlear implantation and examination of ear, nose, and throat are deemed feasible. ${ }^{43}$ A matched control study in Canada reported that telehealth is useful in postoperative bariatric surgery advice for rural patients and for overcoming geographical barriers to provide comparable healthcare services to more rural areas. $^{44}$

\section{Plastic surgery}

In patients undergoing plastic surgery, preoperative surveys revealed that the majority, $73 \%$, of patients preferred in-person follow-up visits in the clinic. However, the postoperative survey distributed after the telehealth encounter found that nearly $100 \%$ of patients were satisfied with the telehealth experience. ${ }^{45}$

\section{Urology}

A review of original research within the past 10 years describing telehealth in urology reported that telehealth technologies, when used, are safe, effective, and satisfactory for patients and providers. ${ }^{46}$

\section{Hypertension}

Telemonitoring of hypertension in pregnancy is becoming increasingly common. Several studies describe potential benefits of patientled remote monitoring, including fewer hospital visits, better blood pressure control, better management in higher risk pregnancies, and cost savings. For surgical training, it is most likely to be a common future practice. $^{47-49}$

\section{Oncology}

The patient-doctor relationship is vital for all healthcare aspects, and it is of great value for patients with cancer and those requiring palliative care. A qualitative study in the United States reported that the majority of patients favored having an opportunity for telemedicine video visits. They felt that the doctor-patient relationship would not suffer, and that video-based telemedicine would be accepted in the case of oncology patients receiving palliative care. ${ }^{50-52}$

\section{Wearable devices}

Telehealth can significantly assist patients who are technology oriented, and a new trend of wearable devices might take over compared to a fixed web-based system. ${ }^{53-55}$ However, with new technologies, the need for safety data rises and might require legislation and proposals such as algorithm-based access control and data sharing. Algorithm-based privacy together with cryptography-based blockchain seem to have the potential to change the way privacy is managed in telehealth. ${ }^{56}$ 


\section{Multiple sclerosis}

The telemedicine program in Albania has improved access to specialized care in a number of specialty disciplines. Almost $80 \%$ of the patients did not require transfer to tertiary centers and were kept for further treatment at regional centers. ${ }^{57}$ The majority of participants reported in a study of multiple sclerosis showed that they would recommend telemedicine visits to others (97.1\%), rating it easy to connect via telemedicine $(94.3 \%)$, and they expressed appreciation for virtual house calls due to convenience and similarity to in-clinic visits. ${ }^{58}$

\section{Urgent care}

An article from the United States concluded that patients facing inequities from rural areas were able to access better healthcare by utilizing the virtual urgent care. ${ }^{59}$ In a recent Cochrane review and article from Brazil, the United Kingdom, and India, it was found that although telehealth might be useful in theory in developing countries or rural areas due lack of doctors and nurses, ultimately patients should feel confident on the quality of care provided. Additional research and funding are required for more randomized controlled trials with stricter methods in order to reduce the uncertainties associated with study outcomes. ${ }^{60,61}$

Involvement of patients in planning services and products based on these new technologies would be advisable to overcome barriers and increase awareness about privacy and the confidentiality of data. ${ }^{62}$ Changing patient as well as doctor perspectives will remain a challenge in telehealth. As for now, it seems many still prefer traditional consultations. ${ }^{63,64}$

\section{Motor neuron disease}

In managing patients with motor neuron disease with telemonitoring, the findings suggest that this approach is empowering and effective in promoting patients' well-being, while potentially reducing unnecessary clinical contact. ${ }^{65}$

\section{Dentistry}

Tele-dentistry may be useful for dental public health to increase the quality of the care by improving access, professional education, and patient satisfaction. The benefits include costeffective health equity services, improved dental knowledge, and reduced consultation waiting time. However, there are obstacles to overcome such as limited infrastructure and professional resistance. ${ }^{66}$

\section{Quality of Technology}

Telehealth is directly related to the quality of the technology used, such as speed of Internet, $3 \mathrm{G}$ versus $4 \mathrm{G}$, fiber optic versus dial-up broadband, all of which provide inconsistent service. This is supported by studies suggesting that inadequate broadband infrastructure in rural areas prevents telemedicine. This barrier to care associated with physician shortages may explain the low rates of telemedicine use among rural patients. ${ }^{67,68}$

Introduction of $5 \mathrm{G}$ Internet is likely to enhance the quality of communication. ${ }^{69}$ Similar to other online technologies and modalities, telehealth, including cloud data storage and retrieval, will develop at a faster pace due to the emerging $5 \mathrm{G}$ technology. ${ }^{70}$ This has an added benefit for surgical specialties with the potential merging of augmented reality video (local site) with the virtual reality video (remote site) and accurate visualization. ${ }^{71}$

The Society for Behavioral Medicine recommends expanding access to high-speed, high-definition Internet and increasing broadband width for rural communities in the United States to increase telehealth opportunities for populations facing location barriers to accessing quality healthcare. ${ }^{72}$ Newer studies are also looking into the 
applications of wearable technology, with mobile devices becoming mature and established as a scientific domain. ${ }^{73,74}$ Current research should bring progress toward sustainable delivery of valuable recommendations, with seamless monitoring and a faster pace due to emerging $5 \mathrm{G}$ technology and implementation of useful telehealth services in low-resource areas..$^{55,75}$

The challenge of reliable Internet service becomes more obvious in developing countries where finances play a vital role. Families understandably have to choose to meet their basic needs over high-speed Internet, good quality computer, and web camera. Governments in developing countries are struggling to provide basic needs for their citizens rather than investing substantial amounts on high-speed universal Internet for all for its citizens. For example, among 24,055 primary care units in Brazil, only $50.1 \%$ had Internet access, and $32.71 \%$ of them claimed to be involved in telehealth services in $2014 .{ }^{76}$ On the other hand, there is a need for guidance and governance on the development and validation of new apps and devices and for the implementation of mobile health technology in healthcare systems in both high- and lowincome settings. All this might be accelerated by high-quality randomized controlled trials. ${ }^{77-79}$ In addition, further mechanisms and supplemental funding are needed to address the continued lack of resources to enhance rural Internet connectivity, including infrastructure, research, and regulatory reform, especially in developing countries..$^{80,81}$

\section{Cost-Effectiveness}

In the absence of an established hospital or community clinic space, there are initial expenses involved in setting up a clinic, especially in remote or rural locations. These include a computer, printer, camera and Internet, clinic space, and the expense associated with staffing a clinic. These costs must then be evaluated in light of the benefits patients have in reduced travel time and greater ability to keep appointments. It is reported that several specialties find telehealth a costeffective modality, but this assessment is not universal. Thus, telehealth has not yet gained the support of all healthcare sectors as a cost saving modality. ${ }^{82-85}$

The application of telemedicine needs time to evolve and is not ready for application as a tool of universal health modality. Rather, it is specialty limited as supported by the results of randomized control trials and articles on specialty areas such as oncology, mental health, chronic health conditions, ICUs, and pediatrics, where it is deemed as cost-effective and of better care value. ${ }^{86-91}$

In a study in the United States, 977 rural ED responding to a survey, $46 \%$ of them were not using telehealth but have considered its use. ${ }^{92}$ In a cohort study, tele-screening was an effective and safe way for this ED to expand the hours in which patients were screened by a healthcare provider in triage-achieved the same level of efficiency as in-person screening by the end of the pilot study. ${ }^{93}$

In low-income countries where specialists are not readily available, telehealth has shown to be feasible in the diagnosis of surgical site infections, with the potential to serve as an effective alternative or adjunct for delivering comprehensive and high-quality mental healthcare. ${ }^{94}$

Preliminary studies suggest that telemedicine may be a safe and cost-effective approach to assist in the medical care of select patients with acute concussion and persistent post-concussion symptoms in children in rural Canada. ${ }^{95}$ The results of systematic review jointly from the 
United Kingdom and Norway suggest that tele-mentoring has a similar safety and efficacy profile as on-site mentoring and is cost-effective in general surgery. ${ }^{96}$

For infectious diseases, it has been shown in a community hospital setting that telehealth led to reduced broad-spectrum antimicrobial utilization, increased infectious disease consultations, and reduced antimicrobial expenditure. ${ }^{97}$ Recently, the Infectious Diseases Society of America supported the appropriate and evidence-based use of telehealth technologies to provide up-to-date, timely, cost-effective subspecialty care to resource-limited populations. ${ }^{98}$

In Iowa and South Dakota, telemedicine screening reliably detected referral-warranted retinopathy of prematurity in at-risk premature infants at two remote sites, with no poor outcomes over 11 months, and good outcomes were noted in all cases, with no patients progressing beyond stage $3 .{ }^{99}$

Inappropriate referrals cost a significant amount to a health institute. A recent study included primary care clinicians who conducted over 3,800 e-Consults for which dermatology, endocrinology, and hematology-oncology were the most common. A national survey in the United States indicated that over one in four primary care centers reported that the e-Consult avoided a referral altogether or a referral to the wrong specialty $(26.3 \%)$ and avoided unnecessary diagnostics/procedures (26.1\%). In $75 \%$ of e-Consults, primary care centers reported an improved care plan, with 50\% reporting that the e-Consult was educational. ${ }^{100}$

In Brazil, tele-electrocardiogram services implemented in 79 municipalities in five states showed that this service fills a gap in specialized care in the public system and can improve access to a basic exam in remote and underserved regions. ${ }^{101}$

A review from the United States of a multidisciplinary approach reported that tele-neurology effectively reduced travel costs and times. There was high patient satisfaction and reduced disparity for general and specialized neurological care. ${ }^{102}$

A pilot randomized controlled trial in Australia reported that telehealth monitoring intervention improved patient's health outcomes and quality of life at no additional cost. ${ }^{103}$ Another article stated that the use of tele-stroke is cost-effective for reducing stroke complications and disabilities. Although there are several barriers to providing a tele-stroke service, telehealth does provides an accurate diagnosis and appropriate treatment. ${ }^{104}$

A small study in Spain on inflammatory bowel disease suggested a high probability of the telehealth platform being more cost-effective than standard and telephone care at least in the short term. ${ }^{105}$

Another factor that undermines cost effectiveness is the need for staff training. Not all healthcare staff are confident about providing telehealth, and training identifies more awareness and education requiring investment in training. ${ }^{106}$

Telehealth is a relatively well-established modality of care provision in developed countries. To maximize its global potential, more time, financial support, and commitment are essential. A cost analysis from Argentina and Singapore reported that telemedicine and telehealth technologies can be used to strengthen medical services and overcome many of the barriers that previously existed by providing safe, accessible, cost-effective, and convenient healthcare service. ${ }^{107-109}$ 
A narrative review from Australia on telemedicine in dementia reported that although it is costeffective and productive in accessing rural areas, there is a preference for face-to-face consultation. ${ }^{110}$

A pan-European randomized controlled trial assessed the 10-year risk for fatal myocardial infarction. Analyzing cost savings related to the integration of telemedical features into diabetes management showed that it iscosteffective. ${ }^{111}$ Studies from Norway and the United States emphasized the value of patient benefit and cost effectiveness of telehealth in the management of asthma and severe cases of chronic obstructive pulmonary disease. ${ }^{112,113}$ A European, multi-country review on cost saving in mobile stroke units suggested that more research is needed to answer this question satisfactorily. ${ }^{114} \mathrm{~A}$ study in Switzerland found that telehealth is feasible and cost-effective among individuals consulting for pre-travel advice at a specialized clinic. There is considerable interest in telemedicine, particularly among older and immunocompromised travelers. ${ }^{115}$ A study from China and another conducted in rural Pakistan found that patients' adoption intention is a function of traveling cost, attitudes, and its usefulness. High traveling cost had the most significant negative influence on adoption intention. Patients with shorter distance to travel prefer more using telemedicine. ${ }^{116}$

\section{DISCUSSION}

Table 2 lists the key conclusions from this 2-year assessment of studies in the application of telehealth. Telehealth is considered to be a modality of health provision for rural and remote areas, but this is changing, especially as resources are stretched and patient expectations are rising. It is emerging as a valuable tool for all levels of healthcare. Governments of low-income countries tend to spend comparatively less on healthcare, and because telehealth is a relatively newer concept, the allocated funding would be even less.

Recent data build a strong case to utilize telehealth beyond rural and remote areas. Involvement of the private sector and initiatives wherein it works alongside government institutions is required. If needed, new laws should be passed through legislative institutions to expedite telehealth provision, making it a regular feature of local health departments. To this end, more needs to be done to provide fast, reliable Internet connectivity, especially

Table 2. Key conclusions from a 2-year assessment (2018-2019) of studies in the application of telehealth Drivers Consideration

\begin{tabular}{|ll|}
\hline Healthcare staff & - All need more training, education, and understanding of telehealth and its benefits. \\
\hline Patients & - Patients generally have a friendly approach toward telehealth. \\
& - Greater awareness is needed. \\
\hline Media & - Media can play a positive role in creating awareness about telehealth usage. \\
\hline Internet access & - Rural and remote areas require universal Internet access. \\
& - Quality should be as good as urban facilities. \\
\hline Cost effectiveness & - Not all health specialties are witnessing the cost-effective benefits of telehealth. \\
& - More research is needed to make it cost-effective.
\end{tabular}


between rural underdeveloped areas and regional health facilities.

Preference for face-to-face physical consultation with a doctor is still predominant. This may contribute to longer waiting times for front-line specialties. This perspective needs to change, and social media, print media, and tele-media can assist by generating an awareness of telehealth. To make a business case for telehealth, local health authorities should explore establishing virtual health clinics with reliable technology so that patients can use their nearest centers. If done properly, the author believes that a robust business case for feasibility of the service can be made, and it would pay for itself initially, while being cost-effective in the long run.

Studies show that electronic consultations can be cost and administratively effective. Ongoing teaching and training of healthcare staff at all levels would make them confident in providing consistent telehealth service. Telehealth could be part of medical school curriculum combined with postgraduate training through accredited institutions.

Nurses at all levels must become familiar with the concepts of telehealth and, depending upon their specialty, they should be able to practice it and incorporate it in their clinical routine.

Telehealth is not a panacea for healthcare delivery and remains specialty-specific. It is certainly not a replacement for physical consultation when needed, but its value must not be ignored in the 21 st century.

Conflicts of Interest: None.

Funding statement: None.

\section{REFERENCES}

1. Begley K, O’Brien K, Packard K, et al. Impact of interprofessional telehealth case activities on students' perceptions of their collaborative care abilities. Am J Pharm Educ. 2019 May;83(4):6880.

2. de Araújo Novaes M, Sá de Campos Filho A, Diniz PRB. Improving education of medical students through telehealth. Stud Health Technol Inform. 2019 Aug 21;264:1917-18.

3. Prendergast M, Honey M. The barriers and facilitators for nurse educators using telehealth for education. Stud Health Technol Inform. 2019 Aug 21;264:1323-6.

4. Klocek A, Šmahelová M, Knapová L, Elavsky S. GPs' perspectives on eHealth use in the Czech Republic: A cross-sectional mixed-design survey study. BJGP Open. 2019 Jul 23. https://doi.org/10.3399/ bjgpopen19X101655

5. Fadaizadeh L, Shajareh E, Role of telemedicine in pace of consultation and physicians' satisfaction in thoracic surgery ICU. Tanaffos. 2018 Feb;17(2):117-21.

6. Li WW, Zhong J. A review of technologybased interventions in improving type 2 diabetes management in Chinese Americans. Asian Pac Isl Nurs J. 2019;4(1):20-33.

7. Dreizler L, Wanjiku GW. Tele-ECHO for point-of-care ultrasound in rural Kenya: A feasibility study. R I Med J. (2013). 2019 Sep 3;102(7):28-31.

8. Badowski DM, Rossler KL, Gill-Gembala LT. Telehealth simulation with motivational interviewing: Impact on learning and practice. J Nurs Educ. 2019 Apr 1;58(4):221-4.

9. Huang EY, Knight S, Guetter CR, et al. Telemedicine and telementoring in the surgical specialties: A narrative review. Am J Surg. 2019 Oct;218(4):760-6. https://doi. org/10.1016/j.amjsurg.2019.07.018

10. Asiedu GB, Fang JL, Harris AM, Colby CE, Carroll K. Health care professionals' perspectives on teleneonatology through the lens of normalization process theory. Health Sci Rep. 2019 Jan 10;2(2):1-11. https://doi. org/10.1002/hsr2.111 
11. Scott Kruse C, Karem P, Shifflett K, Vegi L, Ravi K, Brooks M. Evaluating barriers to adopting telemedicine worldwide: A systematic review. J Telemed Telecare. 2018 Jan;24(1):4-12.

12. Caver KA, Shearer EM, Burks DJ, Perry $\mathrm{K}$, et al. Telemental health training in the Veterans Administration Puget Sound Health Care System. J Clin Psychol. 2019 May 21. https://doi.org/10.1002/ jclp.22797.

13. Mousa AY, Broce M, Monnett S, Davis E, McKee B, Lucas BD. Results of telehealth electronic monitoring for post discharge complications and surgical site infections following arterial revascularization with groin incision. Ann Vasc Surg. 2019 May;57:160-9.

14. McCord SA, Lynch MG, Maa AY. Diagnosis of retinal detachments by a tele-ophthalmology screening program. J Telemed Telecare. 2019 Apr;25(3):190-2.

15. Giorgis AT, Alemu AM, Arora S, et al. Results from the first teleglaucoma pilot project in Addis Ababa, Ethiopia. J Glaucoma. 2019 Aug;28(8):701-7. https:// doi.org/10.1097/IJG.0000000000001271

16. Prada C, Izquierdo N, Traipe R, Figueroa C. Results of a new telemedicine strategy in traumatology and orthopedics. Telemed $J E$ Health. 2019 Jul 9. https://doi.org/10.1089/ tmj.2019.0090

17. Kohler JE, Falcone RA Jr, Fallat ME. Rural health, telemedicine and access for pediatric surgery. Curr Opin Pediatr. 2019 Jun;31(3):391-8.

18. Garne Holm K, Brødsgaard A, Zachariassen G, Smith AC, Clemensen J. Parent perspectives of neonatal tele-homecare: A qualitative study. $J$ Telemed Telecare. 2019 May;25(4):221-9.

19. Nadar M, Jouvet P, Tucci M, et al. The implementation of a synchronous telemedicine platform linking off-site pediatric intensivists and on-site fellows in a pediatric intensive care unit: A feasibility study. Int J Med Inform. 2019 Sep;129:219-25.
20. Bender W, Hiddleson CA, Buchman TG, Intensive care unit telemedicine: Innovations and limitations. Crit Care Clin. 2019 Jul;35(3):497-509.

21. Kopec IC. Impact of intensive care unit telemedicine on outcomes. Crit Care Clin. 2019 Jul;35(3):439-49.

22. Herasevich V, Subramanian S. Tele-ICU technologies. Crit Care Clin. 2019 Jul;35(3):427-38.

23. Roth DE, Ramtekkar U, Zeković-Roth S. Telepsychiatry: A new treatment venue for pediatric depression. Child Adolesc Psychiatr Clin N Am. 2019 Jul;28(3):377-95.

24. McCarthy M, Leigh G, Arthur-Kelly M. Telepractice delivery of family-centred early intervention for children who are deaf or hard of hearing: A scoping review. $J$ Telemed Telecare. 2019 May;25(4):249-60.

25. Jiménez Galán G, Alia Alia C, Vegue González M, et al. The contribution of telemedicine to hepatitis $\mathrm{C}$ elimination in a correctional facility. Rev Esp Enferm Dig. 2019 Jul;111(7):550-5.

26. Stotts MJ, Grischkan JA, Khungar V. Improving cirrhosis care: The potential for telemedicine and mobile health technologies. World J Gastroenterol. 2019 Aug 7;25(29):3849-56.

27. Lee TC, Kaiser TE, Alloway R, Woodle ES, Edwards MJ, Shah SA. Telemedicine based remote home monitoring after liver transplantation: Results of a randomized prospective trial. Ann Surg. 2019 Sep;270(3):564-72.

28. Piao C, Terrault NA, Sarkar S. Telemedicine: An evolving field in hepatology. Hepatol Commun. 2019 Mar 25;3(5):716-21.

29. Negarandeh R, Zolfaghari M, Bashi N, Kiarsi M. Evaluating the effect of monitoring through telephone (tele-monitoring) on selfcare behaviors and readmission of patients with heart failure after discharge. Appl Clin Inform. 2019 Mar;10(2):261-8.

30. Marcolino MS, Maia LM, Oliveira JAQ, Melo LDR. Impact of telemedicine interventions on mortality in patients with acute myocardial infarction: A systematic 
review and meta-analysis. Heart. 2019 Oct;105(19):1479-86.

31. Zhu Y, Gu X, Xu C. Effectiveness of telemedicine systems for adults with heart failure: A meta-analysis of randomized controlled trials. Heart Fail Rev. 2019 May 24. https://doi.org/10.1007/s10741019-09801-5

32. Friedman DI, Rajan B, Seidmann A. A randomized trial of telemedicine for migraine management. Cephalalgia. 2019 Oct;39(12):1577-85.

33. Spear KL, Auinger P, Simone R, Dorsey ER, Francis J. Patient views on telemedicine for Parkinson disease. $J$ Parkinsons Dis. 2019;9(2):401-4.

34. Wu T, Deng Z, Chen Z, Zhang D, Wu X, Wang R. Predictors of patients' loyalty toward doctors on web-based health communities: Cross-sectional study. J Med Internet Res. 2019 Sep 3;21(9):e14484. https://doi.org/10.2196/14484

35. Gillespie SM, Wasserman EB, Wood NE, Wang H. High-intensity telemedicine reduces emergency department use by older adults with dementia in senior living communities. J Am Med Dir Assoc. 2019 Aug;20(8):942-6.

36. Moo LR, Gately ME, Jafri Z, Shirk SD. Home-based video telemedicine for dementia management. Clin Gerontol. 2019 Aug 20:1-11.

37. Giavina Bianchi M, Santos A, Cordioli E. Dermatologists' perceptions on the utility and limitations of teledermatology after examining 55,000 lesions. J Telemed Telecare. 2019 Aug 14:1357633X19864829.

38. Zakaria A, Maurer T, Su G, Amerson E. Impact of teledermatology on the accessibility and efficiency of dermatology care in an urban safety-net hospital: A pre-post analysis. J Am Acad Dermatol. 2019 Dec;81(6):1446-52. https://doi. org/10.1016/j.jaad.2019.08.016

39. Lee JY, Chan CKY, Chua SS, et al. Telemonitoring and team-based management of glycemic control on people with type 2 diabetes: A cluster-randomized controlled trial. J Gen Intern Med. 2020 Jan;35(1):87-94. https://doi.org/10.1007/ s11606-019-05316-9

40. Sproch LE, Anderson KP, Cliniciandelivered teletherapy for eating disorders. Psychiatr Clin North Am. 2019 Jun;42(2):243-52.

41. Qian W, Lam TT, Lam HHW, Li CK, Cheung YT. Telehealth interventions for improving self-management in patients with hemophilia: Scoping review of clinical studies. $J$ Med Internet Res. 2019 Jul 10;21(7):e12340. https://doi.org/10.2196/12340

42. Rezaian MM, Brent LH, Roshani S, Ziaee M, et al. Rheumatology care using telemedicine. Telemed J E Health. 2019 May 14. https://doi.org/10.1089/tmj.2018.0256

43. Beule AG. Telemedical methods in otorhinolaryngology. Laryngorhinootologie. 2019 Mar;98(S 01):S129-72.

44. Wang CD, Rajaratnam T, Stall B, Hawa R, Sockalingam S. Exploring the effects of telemedicine on bariatric surgery follow-up: A matched case control study. Obes Surg. 2019 Aug;29(8):2704-6. https://doi. org/10.1007/s11695-019-03930-4

45. Funderburk CD, Batulis NS, Zelones JT, Fisher AH. Innovations in the plastic surgery care pathway: Using telemedicine for clinical efficiency and patient satisfaction. Plast Reconstr Surg. 2019 Aug;144(2):507-16.

46. Castaneda P, Ellimoottil C. Current use of telehealth in urology: A review. World $J$ Urol. 2019 Jul 27. https://doi.org/10.1007/ s00345-019-02882-9

47. Khalil A, Perry H, Lanssens D, Gyselaers W. Telemonitoring for hypertensive disease in pregnancy. Expert Rev Med Devices. 2019 Aug;16(8):653-61.

48. Ayatollahi H, Ghalandar Abadi M, Hemmat M. Web and mobile-based technologies for monitoring high-risk pregnancies. $B M J$ Health Care Inform. 2019 Jun;26(1). https:// doi.org/10.1136/bmjhci-2019-000025

49. Nieto-Calvache AJ, Zambrano MA, Herrera NA, Usma A. Resective-reconstructive treatment of abnormally invasive placenta: 
Inter institutional collaboration by telemedicine (eHealth). J Matern Fetal Neonatal Med. 2019 May 27:1-9.

50. Luz PLD. Telemedicine and the doctor/ patient relationship. Arq Bras Cardiol. 2019 Aug 8;113(1):100-2.

51. Tasneem S, Kim A, Bagheri A, Lebret J. Telemedicine video visits for patients receiving palliative care: A qualitative study. Am J Hosp Palliat Care. 2019 Sep;36(9):789-94.

52. Scurrey S, Garland SN, Thoms J, Laing $\mathrm{K}$. Evaluating the experience of rural individuals with prostate and breast cancer participating in research via telehealth. Rural Remote Health. 2019 Aug;19(3):5269.

53. Loncar-Turukalo T, Zdravevski E, Machado da Silva J, Chouvarda I, Trajkovik V. Literature on wearable technology for connected health: Scoping review of research trends, advances, and barriers. J Med Internet Res. 2019 Sep 5;21(9):e14017.

54. Khairat S, Liu S, Zaman T, Edson B, Gianforcaro R. Factors determining patients' choice between mobile health and telemedicine: Predictive analytics assessment. JMIR Mhealth Uhealth. 2019 Jun 8;7(6):e13772. https://doi.org/10.2196/13772

55. Mosconi P, Radrezza S, Lettieri E, Santoro E. Use of health apps and wearable devices: Survey among Italian associations for patient advocacy. JMIR Mhealth Uhealth. 2019 Jan 15;7(1):e10242.

56. Ruotsalainen P, Blobel B. Digital pHealth Problems and solutions for ethics, trust and privacy. Stud Health Technol Inform. 2019;261:31-46.

57. Latifi R, Parsikia A, Boci A, Doarn CR, Merrell RC. Increases access to care through telemedicine in Albania: An analysis of 2,724 patients. Telemed $J$ E Health. 2019 Mar 20. https://doi. org/10.1089/tmj.2018.0338.

58. Robb JF, Hyland MH, Goodman AD. Comparison of telemedicine versus inperson visits for persons with multiple sclerosis: A randomized crossover study of feasibility, cost, and satisfaction. Mult Scler Relat Disord. 2019 May 6;36:101258.

59. Khairat S, Haithcoat T, Liu S, Zaman T. Advancing health equity and access using telemedicine: A geospatial assessment. $J \mathrm{Am}$ Med Inform Assoc. 2019 Aug 1;26(8-9): 796-805.

60. Alshahrani A, Stewart D, MacLure K. A systematic review of the adoption and acceptance of eHealth in Saudi Arabia: Views of multiple stakeholders. Int J Med Inform. 2019 Aug;128:7-17.

61. Chellaiyan VG, Nirupama AY, Taneja N. Telemedicine in India: Where do we stand? J Family Med Prim Care. 2019 Jun;8(6):1872-6.

62. Flumignan CDQ, Rocha APD, Pinto ACPN, Milby KMM. What do Cochrane systematic reviews say about telemedicine for healthcare? Sao Paulo Med J. 2019 Jul 15;137(2):184-92.

63. Chudner I, Drach-Zahavy A, Karkabi $\mathrm{K}$. Choosing video instead of in-clinic consultations in primary care in Israel: Discrete choice experiment among key stakeholders-patients, primary care physicians, and policy makers. Value Health. 2019 Oct;22(10):1187-96. https:// doi.org/10.1016/j.jval.2019.05.001

64. Fagerlund AJ, Holm IM, Zanaboni P. General practitioners' perceptions towards the use of digital health services for citizens in primary care: A qualitative interview study. BMJ Open. 2019 May 5;9(5): $\mathrm{e} 028251$.

65. Ando H, Ashcroft-Kelso H, Halhead R, et al. Experience of telehealth in people with motor neurone disease using noninvasive ventilation. Disabil Rehabil Assist Technol. 2019 Sep 12:1-7. https://doi.org/10.1080/ 17483107.2019.1659864

66. Böhm da Costa C, Peralta FDS, Ferreira de Mello ALS, How has teledentistry been applied in public dental health services? An integrative review. Telemed J E Health. 2019 Oct 1. https://doi.org/10.1089/ tmj.2019.0122 
67. Drake C, Zhang Y, Chaiyachati KH, Polsky D. The limitations of poor broadband internet access for telemedicine use in rural America: An observational study. Ann Intern Med. 2019 Sep 3;171(5):382-4. https://doi.org/10.7326/M19-0283

68. Wilcock AD, Rose S, Busch A, Huskamp HA. Association between broadband internet availability and telemedicine use. JAMA Intern Med. 2019 Jul 29. https://doi. org/10.1001/jamainternmed.2019.2234

69. Winter B, Wendt $\mathrm{M}$, Waldschmidt $\mathrm{C}$, Rozanski M, et al. $4 \mathrm{G}$ versus 3G-enabled telemedicine in prehospital acute stroke care. Int J Stroke. 2019 Aug;14(6):620-9.

70. Stefano GB, Kream RM. The microhospital: $5 \mathrm{~g}$ telemedicine-based care. Med Sci Monit Basic Res. 2018 Jul 14;24:103-4.

71. Venkata HS, Alsadoon A, Prasad PWC, et al. A novel mixed reality in breast and constructive jaw surgical tele-presence. Comput Methods Programs Biomed. 2019 Aug;177:253-268.

72. Ford S, Buscemi J, Hirko K, Laitner M, et al. Society of Behavioral Medicine (SBM) urges congress to ensure efforts to increase and enhance broadband Internet access in rural areas. Transl Behav Med. 2019 Mar 11. https://doi.org/10.1093/tbm/ibz035

73. Loncar-Turukalo T, Zdravevski E, Machado da Silva J, Chouvarda I, Trajkovik V. Literature on wearable technology for connected health: Scoping review of research trends, advances, and barriers. $J$ Med Internet Res. 2019 Sep 5;21(9):e14017.

74. Sim I. Mobile devices and health. $N$ Engl $J$ Med. 2019 Sep 5;381(10):956-68.

75. Johansson A, Esbjörnsson M, Nordqvist P, et al. Dataset on multichannel connectivity and video transmission carried on commercial 3G/4G networks in southern Sweden. Data Brief. 2019 Jun 25;25:104192.

76. Dos Santos AF, Mata-Machado ATGD et al. Implementation of telehealth resources in primary care in Brazil and its association with quality of care. Telemed $J$ E Health. 2019 Oct;25(10):996-1004. https://doi. org/10.1089/tmj.2018.0166
77. Varghese FP, VandenBos GR. Clinical apps and public service settings: Innovations, diverse applications, and limits. Psychol Serv. 2019 May;16(2):183-7.

78. Jogova M, Shaw J, Jamieson T. The regulatory challenge of mobile health: Lessons for Canada. Healthc Policy. 2019 Feb;14(3):19-28.

79. Gyselaers W, Lanssens D, Perry H, Khalil A. Mobile health applications for prenatal assessment and monitoring. Curr Pharm Des. 2019;25(5):615-23.

80. Leath BA, Dunn LW, Alsobrook A, Darden ML. Enhancing rural population health care access and outcomes through the telehealth EcoSystem $^{\mathrm{TM}}$ model. Online J Public Health Inform. 2018 Sep 21;10(2):e218.

81. St Clair M, Murtagh D. Barriers to telehealth uptake in rural, regional, remote Australia: What can be done to expand telehealth access in remote areas? Stud Health Technol Inform. 2019 Aug 8;266:174-82.

82. Jiang X, Ming WK, You JH. The costeffectiveness of digital health interventions on the management of cardiovascular diseases: Systematic review. J Med Internet Res. 2019 Jun 17;21(6). https://doi.org/ $10.2196 / 13166$

83. Ellis MJ, Boles S, Dirksen V, et al. Evaluation of a pilot paediatric concussion telemedicine programme for northern communities in Manitoba. Int J Circumpolar Health. 2019 Dec;78(1). https://doi.org/10.1080/22423982. 2019.1573163

84. Fasterholdt I, Gerstrøm M. Cost-effectiveness of telemonitoring of diabetic foot ulcer patients. Health Informatics $J .2018$ Sep;24(3):245-58.

85. Khanna M, Gowda GS, Bagevadi VI, et al. Feasibility and utility of teleneurorehabilitation service in India: Experience from a quaternary center. $J$ Neurosci Rural Pract. 2018 OctDec;9(4):541-4.

86. Kadel R, Evans-Lacko S, Tramarin A, Stopazzolo G. Cost-effectiveness of televideo-consultation for the neuro-surgical emergency management at the general 
hospitals in Italy. Front Neurosci. 2018 Dec 4;12:908.

87. Gilboa Y, Maeir T, Karni S, et al. Effectiveness of a tele-rehabilitation intervention to improve performance and reduce morbidity for people post hip fracture - Study protocol for a randomized controlled trial. BMC Geriatr. 2019 May 20;19(1):135.

88. Ownsworth T, Chambers S, Aitken JF, et al. Evaluation of a telehealth psychological support intervention for people with primary brain tumour and their family members: Study protocol for a randomised controlled trial. Eur J Cancer Care (Engl). 2019 Jul;28(4):e13132.

89. Serhal E, Lazor T, Kurdyak P, Crawford A, et al. A cost analysis comparing telepsychiatry to in-person psychiatric outreach and patient travel reimbursement in Northern Ontario communities. $J$ Telemed Telecare. 2019 Jun 24:1357633X19853139.

90. Maia MR, Castela E, Pires A, Lapão LV. How to develop a sustainable telemedicine service? A pediatric telecardiology service 20 years on - An exploratory study. $B M C$ Health Serv Res. 2019 Sep 23;19(1):681. https://doi.org/10.1186/s12913-019-4511-5

91. Dózsa C, Jankus K, Mariann Helter T. Structural changes in the Hungarian healthcare system between 2000 and 2017. Value Health Reg Issues. 2019 Sep;19:92-8.

92. Zachrison KS, Boggs KM, Hayden EM, Espinola JA, Camargo CA Jr. Understanding barriers to telemedicine implementation in rural emergency departments. Ann Emerg Med. 2019 Aug 29. https://doi.org/10.1016/j. annemergmed.2019.06.026

93. Rademacher NJ, Cole G, Psoter KJ, et al. Use of telemedicine to screen patients in the emergency department: Matched cohort study evaluating efficiency and patient safety of telemedicine. JMIR Med Inform. 2019 May 8;7(2):e11233.

94. Malhotra S, Chakrabarti S, Shah R. A model for digital mental healthcare: Its usefulness and potential for service delivery in low- and middle-income countries. Indian $J$ Psychiatry. 2019 Jan-Feb;61(1):27-36.

95. Ellis MJ, Russell K. The potential of telemedicine to improve pediatric concussion care in rural and remote communities in Canada. Front Neurol. 2019 Aug 2;10:840.

96. Erridge S, Yeung DKT, Patel HRH, Purkayastha S. Telementoring of surgeons: A systematic review. Surg Innov. 2019 Feb;26(1):95-111.

97. Shively NR, Moffa MA, Paul KT, et al. Impact of a telehealth-based antimicrobial stewardship program in a community hospital health system. Clin Infect Dis. 2019 Sep 5. https://doi.org/10.1093/cid/ciz878.

98. Young JD, Abdel-Massih R, Herchline $\mathrm{T}$, et al. Infectious Diseases Society of America position statement on telehealth and telemedicine as applied to the practice of infectious diseases. Clin Infect Dis. 2019 Apr 24;68(9):1437-43.

99. Begley BA, Martin J, Tufty GT, Suh DW. Evaluation of a Remote telemedicine screening system for severe retinopathy of prematurity. $J$ Pediatr Ophthalmol Strabismus. 2019 May 22;56(3):157-61.

100. Olayiwola JN, Potapov A, Gordon A, Jurado J. Electronic consultation impact from the primary care clinician perspective: Outcomes from a national sample. J Telemed Telecare. 2019 Sep;25(8):493-8.

101. Alkmim MB, Silva CBG, Figueira RM, Santos DVV. Brazilian National Service of Telediagnosis in electrocardiography. Stud Health Technol Inform. 2019 Aug 21;264:1635-6.

102. Patel UK, Malik P, DeMasi M, Lunagariya A, Jani VB. Multidisciplinary approach and outcomes of tele-neurology: A review. Cureus. 2019 Apr 8;11(4):e4410.

103. Bohingamu Mudiyanselage S, Stevens J, Watts JJ, et al. Personalised telehealth intervention for chronic disease management: A pilot randomised controlled trial. J Telemed Telecare. 2019 Jul;25(6):343-52. 
104. Halbert K, Bautista C. Telehealth use to promote quality outcomes and reduce costs in stroke care. Crit Care Nurs Clin North Am. 2019 Jun;31(2):133-9.

105. Del Hoyo J, Nos P, Bastida G, Faubel R. Telemonitoring of Crohn's Disease and Ulcerative Colitis (TECCU): Costeffectiveness analysis. $J$ Med Internet Res. 2019 Sep 13;21(9). https://doi. org/10.2196/15505

106. Greiwe J. Using Telemedicine in a Private Allergy Practice. J Allergy Clin Immunol Pract. 2019 Nov - Dec;7(8):2560-7. https://doi.org/10.1016/j.jaip.2019.07.012

107. Chouvarda I, Maramis C, Livitckaia K, et al. ENJECT Working Group Network. Connected health services: Framework for an impact assessment. $J$ Med Internet Res. 2019 Sep 3;21(9). https://doi. org/10.2196/14005

108. Aponte-Tinao LA, Farfalli GL, Albergo JI, et al. Face to face appointment vs. telemedicine in first time appointment orthopedic oncology patients: A cost analysis. Stud Health Technol Inform. 2019 Aug 21;264:512-15. https://doi. org/10.3233/SHTI190275

109. Krishnan A, Finkelstein EA, Levine E, et al. A digital behavioral weight gain prevention intervention in primary care practice: Cost and cost-effectiveness analysis. $J \mathrm{Med}$ Internet Res. 2019 May 17;21(5):e12201. https://doi.org/10.2196/12201

110. Haralambous B, Subramaniam S, Hwang $\mathrm{K}$, et al. A narrative review of the evidence regarding the use of telemedicine to deliver video-interpreting during dementia assessments for older people. Asia Pac Psychiatry. 2019 Sep;11(3):e12355.

111. Fritzen K, Basinska K, Rubio-Almanza $\mathrm{M}$, et al. Pan-European economic analysis to identify cost savings for the health care systems as a result of integrating glucose monitoring based telemedical approaches into diabetes management. J Diabetes Sci Technol. 2019 Nov;13(6):1112-22. https://doi.org/10.1177/1932296819835172

112. Barken TL, Söderhamn U, Thygesen E. A sense of belonging: A meta-ethnography of the experience of patients with chronic obstructive pulmonary disease receiving care through telemedicine. $J A d v$ Nurs. 2019 Dec;75(12):3219-3230. https://doi. org/10.1111/jan.14117

113. Taylor L, Waller M, Portnoy JM. Telemedicine for allergy services to rural communities. J Allergy Clin Immunol Pract. 2019 Nov - Dec;7(8):2554-2559. https:// doi.org/10.1016/j.jaip.2019.06.012

114. Walter S, Grunwald IQ, Helwig SA, et al. Mobile stroke units - Cost-effective or just an expensive hype? Curr Atheroscler Rep. 2018 Aug 29;20(10):49.

115. Rochat L, Genton B. Telemedicine for health issues while abroad: Interest and willingness to pay among travellers prior to departure. J Travel Med. 2018 Jan 1;25(1). https://doi.org/10.1093/jtm/ tay028

116. Zhang X, Zaman BU. Adoption mechanism of telemedicine in underdeveloped country. Health Informatics J. 2019 Sep 30:1460458219868353. https://doi. org/10.1177/1460458219868353

Copyright Ownership: This is an open access article distributed in accordance with the Creative Commons Attribution Non Commercial (CC BY-NC 4.0) license, which permits others to distribute, adapt, enhance this work non-commercially, and license their derivative works on different terms, provided the original work is properly cited and the use is noncommercial. See: http://creativecommons. org/licenses/by-nc/4.0. 